\title{
Joaquim Tenreiro - O processo de modernização do móvel Brasileiro
}

\section{Joaquim Tenreiro - The modernization process of Brazilian furniture}

DOI: 10.46814/lajdv3n1-006

Recebimento dos originais: 30/10/2020

Aceitação para publicação: 23/12/2020

\section{Myrna de Arruda Nascimento}

Doutora

Instituição: Universidade de São Paulo (FAUUSP) e Centro Universitário SENAC

Endereço: Centro Universitário Senac - Av. Eng. Eusébio Stevaux, 823 - Santo Amaro, São Paulo SP, 04696-000; Faculdade de Arquitetura e Urbanismo da Universidade de São Paulo -Rua do Lago, 876- Butantã, São Paulo - SP, 05508-080

E-mail:myrna@usp.br; myrna.anascimento@sp.senac.br; myrnanas@gmail.com

\author{
André Moreira de Lima \\ Pòs graduação/Especialização em Design para Movelaria \\ Endereço: Rua Cuminapanema, 117 \\ E-mail: and.moreiralima@gmail.com
}

\begin{abstract}
RESUMO
O projeto tem como principal objetivo o estudo da experimentação com madeira para a construção de móveis e também o estudo de uma identidade visual particular, criada por Joaquim Tenreiro para o contexto do design brasileiro contemporâneo. Este artista e designer procurou projetar móveis ao longo da sua atuação profissional, buscando a leveza visual aliada às características da cultura brasileira, produzindo uma tradução dos movimentos artísticos e arquitetônicos que influenciaram a produção do design nacional (baseado até então no estilo europeu) a partir dos movimentos de vanguarda do século XX. Seu trabalho constrói uma ponte entre a Arte, o Design e a sociedade brasileira, visto que o autor investigava a representação visual do Brasil a partir da observação e análise da arquitetura, do design (principalmente em nível internacional), e das artes plásticas e aplica aspectos de linguagem e elementos gráficos no mobiliário, valorizando a estética proposta e sua utilidade prática.
\end{abstract}

Palavras-chave: arte, design, experimentação, madeira, modernização, Joaquim Tenreiro.

\begin{abstract}
This Project aims mainly the wood's experimentation study for the furniture construction and the visual identity created by Joaquim Tenreiro for the contemporary Brazilian design context. This designer and artist looked for the furniture production throughout his career, seeking visual weightlessness combined with Brazilian culture character, producing an artistic and architectonic movements' translation which influenced the national design production (until then based on European style) from the vanguard movements of the 20th century. His work establishes a bridge between Art, Design and Brazil's society, since it investigated the country's visual representation as from observation and analysis of architecture, design (mainly in international level) and plastic arts applying aspects of language and graphic elements on the furniture, valuing the esthetic proposal and its utility.
\end{abstract}

Keywords: art, design, experimentation, wood, modernization, Joaquim Tenreiro. 


\section{INTRODUÇÃO}

É necessário observar que Tenreiro nascido em Portugal, conseguiu investigar a originalidade de traços brasileiros nos móveis e desprender a forte influência do estilo europeu barroco de seu país, tão presente e marcante em grande parte da produção moveleira nacional, naquela época (expressivamente durante a década de 50). Esta produção não tinha grandes aproximações com o que acontecia no meio cultural na época, com relação aos movimentos de vanguarda no campo das artes, que tanto influenciaram a arquitetura e a comunicação visual da época.

\section{OBJETIVO DA PESQUISA}

O objetivo do projeto foi compreender a produção do autor e sua inserção nos meios artísticos (visto que Tenreiro era também escultor), e como isto influenciou a funcionalidade dos produtos por ele projetados.

A partir dos levantamentos iniciais da pesquisa identificamos um novo objetivo para a pesquisa, procurando identificar como se deu a construção e a proposta de um novo paradigma a partir da atuação profissional de Tenreiro, procurando compreender como ele pôde ajudar na construção da identidade própria do Brasil, desapegando-se de conceitos de beleza de seu continente natal (Europa), adotando um estilo atemporal e original.

\section{METODOLOGIA}

A metodologia que pretendíamos desenvolver nesta pesquisa se modificou em alguns aspectos desde o projeto inicial, pois durante a pesquisa teórica houve essa percepção descrita nos objetivos do trabalho. A pesquisa teórica se estendeu por mais tempo do que o esperado devido à necessidade de definir com mais especificidade o contexto brasileiro da época: aspectos históricos/culturais e a cultura brasileira como um fator influente para as especificidades das peças de Tenreiro, além dos fatores externos (como o desenvolvimento e definição da arquitetura moderna tipicamente brasileira) e sua relação com a nova abordagem de design moveleiro proposta por ele.

A pesquisa foi dividida em dois momentos principais, onde no primeiro foi coletado o material necessário para a análise (desde livros específicos sobre Tenreiro até materiais que abordam um contexto mais geral do design brasileiro do século $\mathrm{XX}$ ), fazendo com que assim o repertório para o desenvolvimento do trabalho se ampliasse e aumentasse a perspectiva sobre o móvel brasileiro. Houve uma busca sobre a aplicação do trabalho de Tenreiro na história do design no Brasil e um reconhecimento de suas obras e técnicas aplicadas a estas. 
No segundo momento, os resultados das análises foram combinados para que a pesquisa fosse redigida de forma coesa e criando, portanto, uma "liga" para unir os elementos históricos contemporâneos a Tenreiro e suas obras, entendendo a lógica de construção de seu mobiliário.

\section{RESULTADOS E DISCUSSÃO}

Tenreiro começou a ser reconhecido como bom artesão pelo seu trabalho durante 10 anos (1933 a 1943) em firmas conhecidas do ramo de móveis (principalmente voltados para o mercado do luxo), como a Laubisch \& Hirth, a Leandro Martins e a Francisco Gomes, empresas reconhecidas e especializadas na oferta de móveis que imitavam os velhos estilos europeus (franceses, portugueses, italianos etc.).

Antes de trabalhar para a Laubisch \& Hirth, Joaquim Tenreiro fora designado para projetar os móveis para a casa do médico e colecionador Francisco Ignácio Peixoto. A casa foi projetada por Oscar Niemeyer, e possuía os traços minimalistas e construtivos da arquitetura moderna instalada no Brasil. Tenreiro deveria, portanto, criar móveis que dialogassem com a característica da arquitetura, adequados aos aspectos visuais da cultura brasileira.

O móvel moderno no Brasil tem a madeira como elemento fundamental para a constituição de sua linguagem [...]. Essa condição procede, aparentemente, da abundância de espécies verificadas no seu vasto território e da forte presença de madeira no cotidiano do país, remontando à sua herança colonial. [MELO, 2008, pg. 13]

Decidindo pela madeira, Tenreiro deveria pensar na forma desses móveis, em como poderiam conciliar sua matéria-prima com as linhas propostas por Niemeyer na concepção da tal casa moderna.

O traço deve ser simples, com coerência formal e lógica construtiva buscando o conforto, além de funcional e resistente. O resultado foi um mobiliário simples, com leveza visual e linguagem adequada para o contexto da proposta.

Em 1943, Tenreiro abriu sua própria loja-oficina: a Langebach e Tenreiro Ltda, no centro do Rio de Janeiro. Em 1947, abriu sua primeira loja em Copacabana, transferindo-a para Ipanema em 1962, e uma filial em São Paulo no ano de 1953. Essa ampliação fez com que trocasse sua oficina por uma espaçosa fábrica para que pudesse conceber seus móveis, já famosos.

Utilizava técnicas curiosas para a concepção de suas peças, baseadas em estudos e experimentações feitas em suas esculturas, como se estas fossem um protótipo dos móveis ou viceversa (visto que a profissão de artista era mantida paralelamente com a de designer). Essa tática era bem-vinda para a construção de seus móveis minimalistas e extremamente simples se comparados com os móveis europeus que eram produzidos pelas firmas pelas quais passou. 


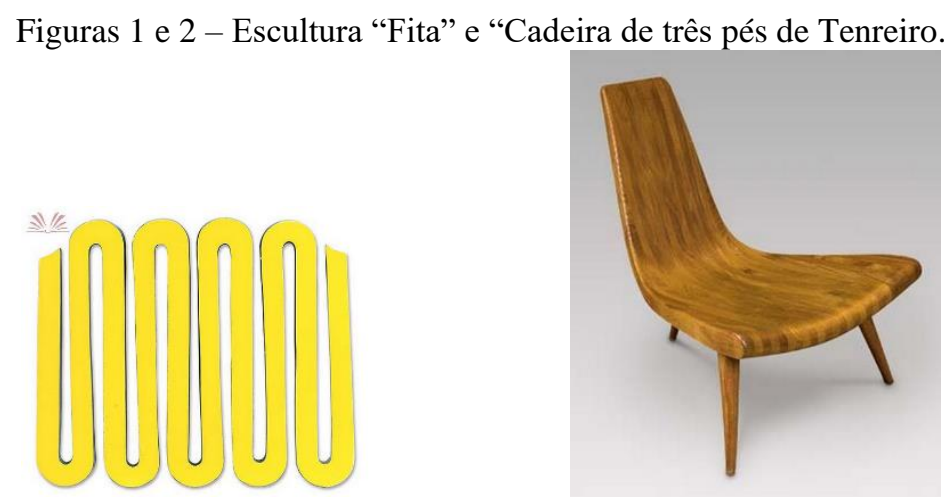

A estrutura de seu mobiliário consistia predominantemente em madeira, adotando técnicas e processos de fabricação diferenciados. Lâminas envergadas, estruturas cilíndricas dobradas e o mínimo de peso possível (tanto físico quanto visual) eram características de suas obras.

Acima temos a escultura "Fita", da década de 70, e a "Cadeira de três pés", de 1947. Nota-se uma técnica parecida entre as duas peças, que consiste no dobramento de madeira para obter curvas. Essa intervenção na madeira (provavelmente consistente de lâminas retiradas de uma tora de madeira a partir do torneamento desta) garante um desenho convidativo e suave para o usuário da cadeira ou para o admirador da escultura.

Figuras 3 e 4 - Escultura sem título e Aparador em Pau-marfim, Joaquim Tenreiro
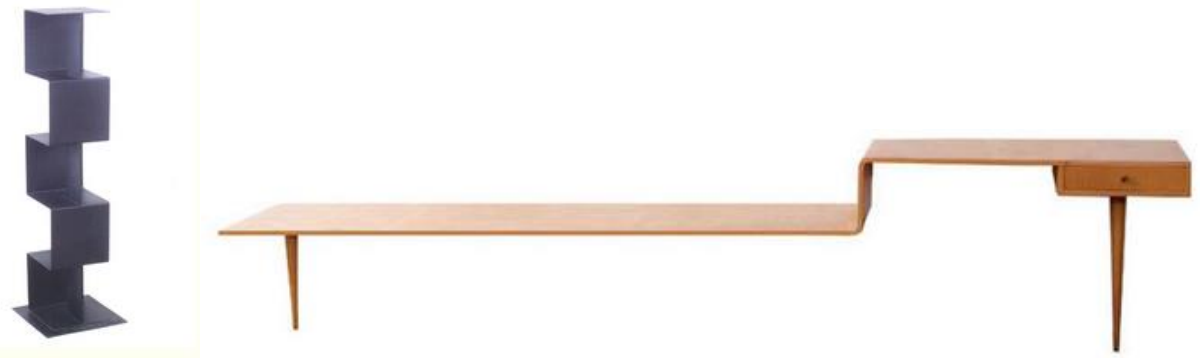

O próximo exemplo traça um paralelo entre a escultura sem título, também datada da década de 70, e o aparador em pau-marfim, da década de 50. Desta vez, a curva não é mais tão suave, é brusca e agressiva, buscando ângulos retos. Isso é aplicado para indicar alguma funcionalidade prática, já que a superfície retilínea sugere um apoio para outros objetos. A leveza visual é garantida pela ausência de saturação de informações visuais, pelas poucas formas e espessuras. Uma característica interessante comum a ambos os casos é a forma de fixação das peças. Não há parafuso ou qualquer elemento que se saliente sobre as peças principais - o encaixe é feito internamente, provavelmente a partir de um sistema de cavilhas. Tudo isso é pensado para que não existam interferências visuais não previstas dentro da proposta. 
Ainda dentro da análise de seus móveis, listarei alguns exemplares de maior expressividade para a discussão de suas produções.

Figura 5. Poltrona Leve, 1942

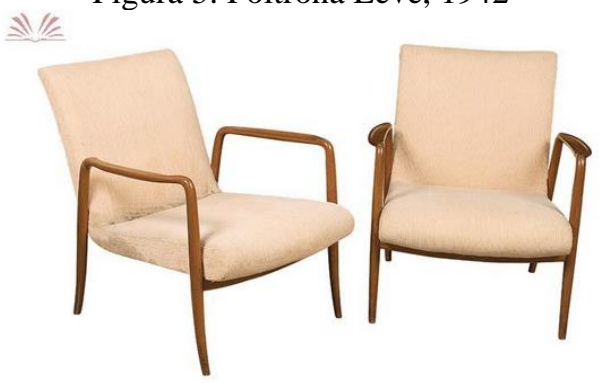

Uma de suas primeiras criações, datada de 1942, a Poltrona Leve possui esse nome justamente por procurar a utilização de linhas absolutamente necessárias para sua composição, dispensando qualquer inflação de formas ou detalhes que não fossem realmente necessários para a concepção de uma poltrona confortável e prática. Sua estrutura é composta por pau-marfim com encosto e assento de espuma revestidos com tecido tipo coco ralado, no modelo em questão. A parte de madeira é uma simples linha, moldada de forma que fosse roliça e com diâmetro pequeno. O dobramento destas "tiras cilíndricas" forma um aro em formato de U, transformando o apoio para os braços e as pernas da cadeira em uma única estrutura.

Tenreiro explicou que "Ela foi concebida obedecendo a um princípio que eu achava que deveria ser seguido pelos móveis modernos brasileiros: a leveza, que não tem nada a ver com o peso em si, mas com a funcionalidade e graciosidade do espaço."

O modelo em tiras (Figura 6, abaixo), concebido também em 1942, também é materializado em pau-marfim, porém com encosto de tiras de couro. A técnica para a obtenção desse modelo remete à escultura "Fita" já mencionada. Uma longa tira de madeira (dessa vez com desenho mais chapado) é dobrada com um raio considerável para que tenha esse desenho curvilíneo e suave. A lógica do apoio dos braços é a mesma da Poltrona Leve, a mesma peça é utilizada para a concepção dos pés da cadeira.

Figura 6. Cadeira de Tiras, 1942

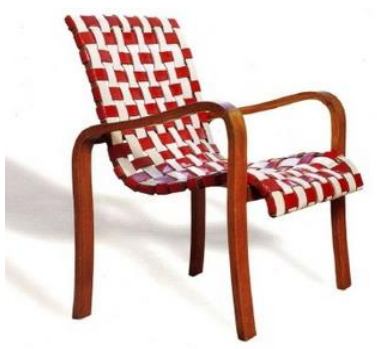

Figura 7. Cadeira de Três Pés, 1947

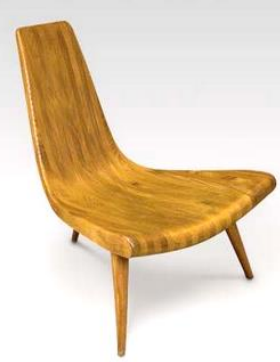


De 1947, essa clássica cadeira de Tenreiro (Figura 7) possui três pés, obviamente, torneados e encaixados com o encosto e assento - esses obtidos em uma única estrutura composta de tiras de até cinco tipos de madeira (jacarandá, imbuia, roxinho, marfim e cabreúva). Essa foi a cadeira escolhida para a construção do modelo em escala. Inicialmente, imaginei que sua forma fosse obtida a partir de dobramento de madeira, porém seria uma técnica que demandaria muito tempo e muitas especificidades em seu processo de fabricação, e como é feita a partir de tiras de madeira maciça (e não um compensado, o que facilitaria a dobra) descartei essa hipótese e imaginei que cada tira fosse cortada com o mesmo perfil semelhante a um bumerangue e então presas uma a outra para o tratamento final da forma, onde uma extremidade tem o tamanho diferente da outra.

Figura 8. Cadeira de Embalo, 1947

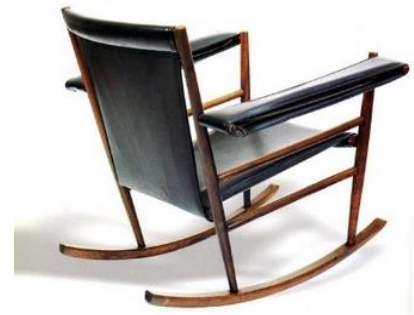

Figura 9, Cadeira Estrutural, 1947

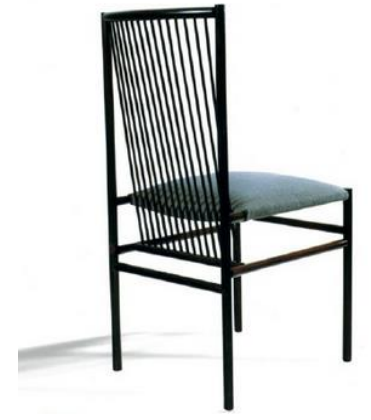

Também de 1947, essa cadeira "de embalo” (Figura 8). tem estrutura em jacarandá, encosto, assento e braços estofados de manta de borracha e pés de madeira curvada. A madeira, nesse caso, não se propõe a mudar de direção, mas ser levemente curva para que tenha a propriedade de balanço. $\mathrm{O}$ raio para o dobramento desses pés é extremamente grande, para que a curva seja sutil o suficiente para que não se torne um incômodo (já que interage diretamente com o usuário do móvel).

Estrutura em Jacarandá, assento estofado revestido de tecido e encosto em varetas de madeira torneadas (Figura 9, acima). Cada vareta possui $3 \mathrm{~cm}$ de espaço entre uma e outra. Essas "linhas de madeira" inclinadas como encosto proporcionam um apoio ergonômico para as costas, como se fosse uma rede rígida. $\mathrm{O}$ desenho da cadeira como um todo é retilíneo e sem curvas programadas, com o foco voltado para a estruturação e firmeza. 
Figura 10. Cadeira com Braços

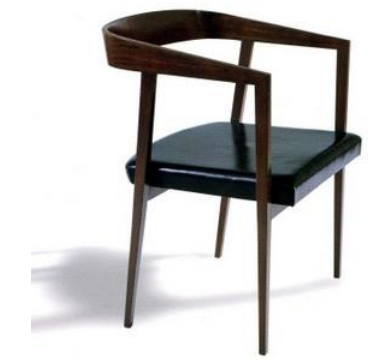

O modelo proposto por Tenreiro em 1960 retoma a ideia de uma única peça formar os braços e os pés da cadeira. Mas dessa vez, essa mesma peça também forma o encosto. Na realidade, essa é a impressão que temos ao analisar a nivelação das peças, e possuem um encaixe e acabamento tão bom que nos iludem. A verdade é que apenas o encosto e os braços são a mesma peça, enquanto os pés são encaixados nesta. Os pés dianteiros são encaixados no mesmo nível e, pelo encaixe interno a partir de cavilhas, a junção é quase imperceptível.

Ainda poderia citar inúmeras criações, mas prefiro focar nestas em que o trabalho com a madeira é mais ressaltado e que traduzem bem o universo que Tenreiro criava para a designação do móvel moderno brasileiro: simples, funcional, prático e ao mesmo tempo intrigante e convidativo.

\section{CONCLUSÕES}

O design brasileiro passou de cópia contemplativa para uma identidade fundamentada e coesa com aspectos locais como a geografia e a cultura. Joaquim Tenreiro teve diversas parcerias em sua carreira, o que também influenciou muito seu trabalho. O que nos deixou foi uma marca, o que o design vindo do Brasil e criado no Brasil têm a dizer. Fomos colonizados por europeus e o aumento demográfico no território se deu por esse povo, portanto o brasileiro dos séculos passados, em sua maioria, tentava rebuscar essa descendência europeia sem considerar que somos um país mestiço. Portanto, é ilógica a ideia de que devemos adotar um estilo "alheio" como o nosso - o que acontecia, por exemplo, no visual europeu dos móveis da Laubisch \& Hirth, ditos "luxuosos" por adotarem um estilo eurocêntrico rebuscado.

Para leigos pode até parecer que Tenreiro fez apenas "esqueletos de móveis", mas ele, junto com Oscar Niemeyer, Sergio Rodrigues, Lucio Costa, e outros, construíram uma identidade autônoma para o povo brasileiro, baseados em seus costumes, em seus hábitos e, principalmente, em sua mistura que se torna tão homogênea e universal quanto o design moderno se propõe a ser. 


\section{REFERÊECIAS}

DE MORAES, Dijon. Análise do design brasileiro. Editora Blucher, $1^{\text {a }}$ edição. São Paulo, 2006.

Brasil Faz Design (5: 2002: São Paulo). Brasil faz design: design e madeiras do Brasil. São Paulo: Banca Catão, 2000.

Lista de obras por bibliografia - Joaquim Tenreiro - Catálogo das Artes. Disponível em: http://www.catalogodasartes.com.br/Lista_Obras_Biografia_Artista.asp?idArtista=337\&txtArtista=Jo aquim\%20Tenreiro. Brasil. Acessado em: 25 de junho de 2014.

JOAQUIM TENREIRO: o mestre da madeira. Coordenação Ricardo Sardenberg; apresentação Marcos Mendonça, Quirino Campofiorito, Janete Costa. São Paulo: Pinacoteca, 2000.

LEAL, Joyce Jonnert. Um olhar sobre o design brasileiro. São Paulo: Workshop, 2003.

LEON, Ethel. Design brasileiro: quem fez, quem faz. Rio de Janeiro: Ed. Senac Rio, 2005

LIMA, Marco Antônio Magalhães. Introdução aos Materiais e Processos para Designers. Rio de Janeiro: Editora Ciência Moderna Ltda., 2006.

MELO, Alexandre Penedo Barbosa de. Design mobiliário moderno brasileiro: aspectos da forma e sua relação com a paisagem. Tese de Doutorado: Alexandre Penedo Barbosa de Melo, São Paulo, 2008.

SANTOS, Maria Cecília Loschiavo dos. Móvel moderno no Brasil. Prefácio Otília Beatriz Fiori Arantes; apresentação Gui Bonsiepe. São Paulo: Studio Nobel, 1995. 